\title{
Adaptation Strategies of Smallholder Farmers to Climate Change and Variability: Evidence from Northern Ghana
}

\author{
*John K. M. Kuwornu¹, Ramatu M. Al-Hassan¹, Prince Maxwell Etwire², Yaw Osei-Owusu ${ }^{3}$ \\ ${ }^{1}$ University of Ghana, Legon, Ghana \\ ${ }^{2}$ CSIR-Savanna Agriculture Research Institute, Tamale, Ghana \\ 3 Conservation Alliance, Ghana \\ *jkuwornu@gmail.com
}

\begin{abstract}
Farmers have been modifying their practices in order to deal with climate change and variability. Even though such practices have been documented in other parts of Africa, information on Ghana and particularly northern Ghana is scanty. This study examines the adaptation strategies of smallholder farmers to climate change and variability in northern Ghana. The paper is based on primary data collected through a household survey, community focus group discussions and key informant interviews in order to identify the adaptation responses of smallholder farmers in northern Ghana to climate change and variability. Several indigenous climate-related practices and technologies categorised into four strategies were identified. In addition, climate related technologies introduced by research, also categorised into four strategies, and were identified as being used by smallholder farmers in northern Ghana. The empirical results of the Friedman test indicates that timing of the onset of the rainy season which informed planting, and soil and plant health related strategies are the most important climate related strategies used by smallholder farmers in securing yield. The policy implication is that practical, timely and reliable information on the onset of the rainy season as well as region specific soil and plant health technologies should be generated and made available to smallholder farmers in northern Ghana to minimise the adverse impacts of climate change.
\end{abstract}

Key Words: Adaptation, Climate Change, Climate Variability, Northern Ghana, Friedman Test

\section{Introduction}

Morton (2004) notes that some of the most important impacts of climate change will be felt by the category of people, mostly referred to as smallholder farmers in developing countries. Agriculture in Ghana is predominantly smallholder in nature with about 90 percent of farm holdings being less than 2 hectares in size. In northern Ghana, these farmers are usually involved in the cultivation of staple grains including maize, rice, millet, sorghum, soybean, cowpea and groundnut, and also engage in the rearing of small ruminants such as sheep and goats (MoFA, 2010). Agricultural producers have been modifying their practices in order to deal with climate change and variability. Adaptation to climate change is already taking place but on a limited basis usually at the farm-level (Boko et al., 2007; Nhemachena and Hassan, 2007). Traditionally, mechanisms for adapting to seasonal and annual climate variability have included sharing of indigenous knowledge on better crop and fish types, farming systems, soils, soil health, water management technologies, integrated pest management and agro forestry systems (FAO, 2009a). As agriculture is directly affected by climate change, adaptation strategies are becoming increasingly important issues for promoting development (Clement et al., 2011). A better understanding of farmer perceptions regarding long-term climatic changes, current adaptation measures and their determinants will be important in informing policy for future successful adaptation of the agricultural sector (Nhemachena and Hassan, 2007). Adaptation is one of the important ways of reducing the long term impacts of climate change and variability (FAO, 2006). Adaptation strategies in the context of climate change are all those practices that are used by smallholder farmers to either get used to, or minimise the effects of climate change and variability. According to Below et al. (2010), it is difficult to distinguish between adaptation to climate change and adaptation to climate variability at the farmer level due to the dynamic nature of adaptation responses. Therefore, in this study, adaptation refers to how smallholder farmers are either modifying their practices or putting in place mechanisms to withstand the adverse effects and impacts of climate change and variability. 
According to FAO (2006), the adaptation strategies adopted by farming households in order to manage the effects of climate variability were categorized into traditional strategies, government-supported strategies, alternative and innovative automatic adaptation strategies, and technology driven strategies. This study categorizes the strategies adopted by smallholder farmers for dealing with the effects of climate change and variability into two, namely indigenous, and introduced adaptation strategies, following the FAO classification. The traditional strategies are what are considered in this study as indigenous strategies. Government-supported strategies are not considered in this study; technology driven, and alternative and innovative automatic adaptation strategies are however considered in this study simply as introduced adaptation strategies. Indigenous adaptation strategies are all those technologies and practices that have or are perceived to have originated from the farmers themselves, be it a novelty by the current generation or a hand-over by previous generations. The relevance of this paper is twofold. First, smallholder farmers' perception of the effectiveness of adaptation strategies in securing yield is explored in this study through their rankings of the strategies. Consequently, the results would enable the government and research institutions to take measures in order to stabilise yields, by up scaling the dissemination of adaptation strategies that are perceived to be effective. Second, most of the empirical work on climate change and agriculture has focused on Europe, the United States, Canada and Australia (Molua and Lambi, 2006). Therefore, this study makes an empirical contribution to the literature on adaptation strategies of smallholder farmers to climate change and variability. It therefore adds to the body of knowledge on adaptation in West Africa. This paper is a follow up to Etwire et al., (2013).

\section{Climate Change Adaptation Strategies}

Indigenous Adaptation Strategies: The literature is replete with several indigenous adaptation strategies that are used by smallholder farmers for adapting to climate change and variability. Table 1 is a compilation of some examples of indigenous adaptation strategies identified from literature.

Table 1: Indigenous Adaptation Strategies

\begin{tabular}{|c|c|}
\hline Indigenous adaptation technology & Author(s) \\
\hline Crop diversification & $\begin{array}{l}\text { Hassan and Nhemachena, 2008; FAO, 2009b; Gbetibouo, 2009; } \\
\text { Deressa et al., } 2010\end{array}$ \\
\hline Multiple cropping & Altieri and Koohafkan, 2008 \\
\hline Change of crops & $\begin{array}{l}\text { FAO, 2006; Molua and Lambi, 2006; FAO, 2009b; Gbetibouo, } \\
2009\end{array}$ \\
\hline Changing location of crops & FAO, 2009b \\
\hline Variety diversification & Altieri and Koohafkan, 2008; Hassan and Nhemachena, 2008 \\
\hline Cultivating short season local varieties & Molua and Lambi, 2006 \\
\hline Cultivating illegal substance & FAO, 2010 \\
\hline Homestead gardening & FAO, 2006; Altieri and Koohafkan, 2008 \\
\hline Varying area cultivated & Molua and Lambi, 2006; Gbetibouo, 2009 \\
\hline Re-sowing/re-planting & FAO, 2006 \\
\hline Increasing planting space & Molua and Lambi, 2006 \\
\hline Changing timing of farm operations & $\begin{array}{l}\text { Molua and Lambi, 2006; Boko et al., 2007; Easterling et al., 2007; } \\
\text { Hassan and Nhemachena, 2008; FAO, 2009b; Gbetibouo, } 2009\end{array}$ \\
\hline Soil organic matter enhancement & Altieri and Koohafkan, 2008 \\
\hline Mulching & Altieri and Koohafkan, 2008; Hassan and Nhemachena, 2008 \\
\hline $\begin{array}{l}\text { Integration of livestock to crop } \\
\text { production }\end{array}$ & $\begin{array}{l}\text { Boko et al., 2007; Easterling et al., 2007; FAO, 2009b; Gbetibouo, } \\
\text { 2009; Deressa et al., 2010; FAO, } 2010\end{array}$ \\
\hline Livestock diversification & Deressa et al., 2010 \\
\hline Wild plant gathering & Altieri and Koohafkan, 2008 \\
\hline Mortgaging land & FA0, 2006; Deressa et al., 2010 \\
\hline Disposing of productive assets & FAO, 2006; Deressa et al., 2010 \\
\hline Engaging in non-farm activities & Hassan and Nhemachena, 2008; FAO, 2010 \\
\hline Joining local credit unions & Deressa et al., 2010; FAO, 2010 \\
\hline Reducing personal expenditures & FA0, 2006; Deressa et al., 2010 \\
\hline
\end{tabular}


Reducing food intake

Employing child labour

Marrying off young children

Undertaking traditional and religious

ceremonies

Migration
FAO, 2006; Deressa et al., 2010; FAO, 2010

Deressa et al., 2010

FAO, 2010

Molua and Lambi, 2006

Boko et al., 2007; Deressa et al., 2010; FAO, 2010

Source: Authors' compilation from literature (2011)

Deressa et al., (2010), classified the indigenous adaptation strategies into two; namely risk-mitigating strategies and coping strategies. FAO (2010) groups the indigenous adaptation strategies into three; namely income coping strategies, cutback strategies and agricultural coping strategies. This paper categorizes the indigenous adaptation strategies into four; namely crop and livestock related strategies; soil related strategies; cultural practice related strategies; and any other indigenous strategies. A crop and livestock related strategy is any combination of practices that seeks to stabilize food and livestock production and to a large extent income; for example, crop diversification and livestock diversification. Soil related strategy is any combination of practices that tend to enhance soil health directly and to a large extent yield, for example, mulching and organic matter enhancement. Cultural practice related strategy is any combination of practices that seek to improve upon farm management; for example, weed management. Any other indigenous strategy is any combination of practices that do not fall into any of the categories above, for example, timing the onset of the rainy season.

Introduced Adaptation Strategies: Introduced adaptation strategies are those technologies that were either developed or promoted by formal research or experimental stations. These were found to be relatively fewer and more organized in the literature than the indigenous adaptation strategies. Table 2 is a compilation of some examples of introduced adaptation strategies identified from literature.

Table 2: Introduced Adaptation Strategies

\begin{tabular}{ll}
\hline Introduced adaptation technology & Author(s) \\
\hline Varieties tolerant to relevant climatic conditions & Hassan and Nhemachena 2008; FAO, 2009b \\
Modernized irrigation system & Hassan and Nhemachena 2008; FAO, 2009b; Gbetibouo \\
& 2009 \\
Improved meteorological forecast & Easterling et al., 2007, FAO, 2009b \\
Farm insurance & FAO, 2009b \\
Good agricultural practices & Easterling et al., 2007 \\
Integrated pest and disease management & Easterling et al., 2007 \\
Integrated soil fertility management & Molua and Lambi 06, ; Easterling et al., 2007; Hassan and \\
& Nhemachena 2008; FAO, 2009b \\
Agro forestry systems & Altieri and Koohafkan 2008 \\
\hline
\end{tabular}
Source: Authors' compilation from literature (2011)

This study also categorizes the introduced adaptation strategies into four; namely improved varieties or breeds strategies; soil and plant health strategies; recommended agricultural practice strategies; and other introduced strategies. Improved varieties or breeds strategy is any combination of technologies that seeks to enhance the smallholder farmer' crops or livestock resilience to climatic shocks, for example, drought or flood tolerant varieties. Soil and plant health strategy is any combination of technologies that have been developed to promote soil and plant heath, for example, application of pesticides and inorganic fertilizers. Recommended agricultural practice strategy is any combination of technologies developed to improve agronomic and husbandry practices such as appropriate planting method, spacing and plant population. Other introduced strategy is any combination of technologies and practices that do not fall into any of the four categories above, for example irrigation.

\section{Methodology}

Data Sources and Method of Analysis: Literature was reviewed in order to identify indigenous and introduced strategies used by smallholder farmers in adapting to climate related events (mainly droughts and 
floods). These were then complemented with focus group discussions at the community level and key informant interviews at some of the academic, research and development institutions working in northern Ghana. Through a multi-stage sampling technique, farm level data was taken from 320 farm households. The respondents then ranked four indigenous and five introduced strategies by research, based on a strategy's effectiveness in ensuring food availability in spite of climate change and variability. The highest ranked strategy was assigned a value of one. A number of methods have been developed for testing rankings; notable among them are the Garrett's rank scoring technique, Kendall's coefficient of concordance and Friedman's two-way analysis of variance without replication by ranks. The Garrett's rank scoring technique converts ranks into percent positions which are then converted into scores by referring to the Garrett's table. Thus for each factor, the scores of the individual rankers are added and the average score is estimated and arranged in either ascending or descending order (Loganathan et al., 2009). The limitation of this method is that it involves a number of steps and does not test the level of agreements between rankers. It does not also appear to test any specific hypothesis. Kendall's coefficient of concordance measures the degree of agreement of rankings by different rankers. The total rank score for each factor is computed and the factor with the least score is ranked as the most preferred. The procedure is similar to Friedman's test which is also described in the next chapter. According to Legendre (2005) there is a close relationship between Friedman's two-way analysis of variance without replication by ranks and Kendall's coefficient of concordance. They address hypotheses concerning the same data and they use the same chi square statistic for testing. They differ only in the formulation of their respective null hypothesis. Whereas the null hypothesis of the Friedman's test focuses on the items being ranked, the Kendall's test focuses on the rankers themselves. This study therefore adopts the Friedman's two-way analysis of variance without replication by ranks, to test the agreement of smallholder farmers' rankings of adaptation strategies.

Following Legendre (2005), the rankings were then subjected to the Friedman's two-way analysis of variance test without replication by ranks. Two hypotheses were tested, first for indigenous strategies and then for introduced strategies as follows;

$\mathrm{H}_{0}$ : There is no difference in smallholder farmers ranking of climate related strategies

$\mathrm{H}_{1}$ : There is difference in smallholder farmers ranking of climate related strategies

The Friedman statistic, $\mathrm{T}$ is given by equation (1);

$$
T=\frac{12}{b k(k+1)} \sum{ }_{i=1}^{k} R^{2}-3 b(k+1)
$$

Where $b$ is number of smallholder farmers, $k$ is number of climate related strategies; $R_{i}$ is the rank sum for the $\mathrm{i}^{\text {th }}$ climate related strategy. $\mathrm{T} \sim \mathrm{X}^{2}{ }_{(\mathrm{K}-1)}$ follows approximately a chi-square distribution with $\mathrm{K}-1$ degrees of freedom.

Reject $\mathrm{H}_{\mathrm{o}}$ if $T>\chi_{(K-1,1-\propto)}^{2}$

\section{Results and Discussion}

Identified Indigenous Adaptation Strategies: Smallholder farmers in northern Ghana use several indigenous practices and technologies in adapting to the effects of climate change and variability. These technologies and practices as indicated were classified into four strategies. The crops and livestock related strategies comprise of six technologies or practices namely mixed cropping, crop rotation, cultivation of full season traditional varieties, livestock production, cultivation of short duration crops and mono cropping. The soil related technologies/practices identified are: making of mounds, manure application, ridging, loosening of soil and creation of bunds or drainage channels were categorised as soil related strategies. Cultural practice related strategy is another categorisation that consists of four identified indigenous agricultural practices namely mulching, regular or early weeding, land rotation and spacing of planting materials. Two distinct indigenous adaptation mechanisms that were reported by smallholder farmers in northern Ghana as being used in dealing with the effects of climate change has being categorised as other indigenous strategies. These are early or late planting and timing of the onset of the rainy season. 
Smallholder Farmer' Ranking of Indigenous Adaptation Strategies: A Friedman test was conducted using SPSS 16.0 software to determine whether there are differences in smallholder farmers' ranking of the four categorised indigenous adaptation strategies. Results of the analysis indicate that there are differences in smallholder farmers' ranking of the four indigenous adaptation strategies. The chi square values were found to be significant for both the overall data (296 observations) and individual regional data for northern Ghana as shown in Table 3.

Table 3: Smallholder Farmer' Ranking of Indigenous Adaptation Strategies

\begin{tabular}{lllll}
\hline Strategy & \multicolumn{3}{c}{ Mean Rank } & \multicolumn{3}{c}{ Region } \\
\cline { 2 - 5 } & Overall & Northern & Upper West & Upper East \\
\hline Other indigenous strategies & 2.15 & 2.13 & 2.36 & 1.96 \\
Crop and livestock related strategies & 2.46 & 2.45 & 2.56 & 2.36 \\
Cultural practice related strategies & 2.53 & 2.45 & 2.82 & 2.39 \\
Soil related strategies & 2.87 & 2.97 & 2.26 & 3.29 \\
Friedman Test Statistics & & & & \\
N & 296 & 143 & 76 & 77 \\
Chi-Square & 47.31 & 30.85 & 8.17 & 44.04 \\
df & 3 & 3 & 3 & 3 \\
Asymp. Sig. & 0.000 & 0.000 & 0.043 & 0.000 \\
\hline
\end{tabular}

Source: Computations from field survey, 2011

Overall, the strategy comprising of early or late planting and timing of rainfall also categorised as 'other indigenous strategy' is ranked by smallholder farmers in northern Ghana to be the most effective strategy used in adapting to climate change and variability. Timing of the onset of the rainy season which informed the planting period was found to be very important in securing yield due to the increasing variability in rainfall. Results of the analysis also show that soil related strategies are ranked as the least effective indigenous strategy used in adapting to the effects of climate change and variability by smallholder farmers in northern Ghana. This could be explained by the fact that introduced soil technologies (for example inorganic fertilizers and compost) are perceived to be superior to indigenous soil technologies (for example manure). Introduced soil technologies are usually more superior because they are generated through well planned researches and therefore perform specific actions such as improving soil nitrogen, phosphorus among others. Introduced soil technologies usually have immediate impact. At the regional level, the rankings of the four indigenous adaptation strategies by smallholder farmers in both the Northern and Upper East regions were found to be the same order as the overall rankings. Results of the analysis for the Upper West Region shows that soil related strategies are ranked as the most effective indigenous strategy used by smallholder farmers in adapting to climate change and variability. Cultural practice related strategies are the least ranked indigenous strategy used for adaptation to climate change and variability.

Identified Introduced Adaptation Strategies: Technologies introduced by research were also found to be used by smallholder farmers in northern Ghana in adapting to the effects of climate change and variability. These technologies have been categorised into four strategies as indicated. It was observed that some farmers were not using any technology introduced by research in adapting to the effects of climate change and variability. Such farmers either relied on indigenous technologies and practices or did nothing. Improved varieties and breeds strategy consists of all technologies that were introduced by research as an improvement upon farmers' variety and breeds such as high yielding varieties, early maturing varieties, drought tolerant varieties and improved breeds. The soil and plant health related strategies comprises of technologies that either improves on soil health or protects field crops. These are application of inorganic fertilizers, compost, herbicides and insecticides. A technology that has to do with crop management or husbandry is categorised as a recommended agricultural-practice strategy. These are harrowing, conservation agriculture, planting during recommended period and planting in rows. Four unique technologies introduced by research in order to help smallholder farmers in northern Ghana to adapt to climate change and variability were also categorised as other introduced strategies. These are planting of trees, irrigation, and establishment of fire belts. 
Smallholder Farmer' Ranking of Introduced Adaptation Strategies: Results of the Friedman test indicate that there are differences in smallholder farmers ranking of the introduced adaptation strategies. The chi square values were found to be significant for both the overall data (320 observations) and individual regional data for northern Ghana as shown in Table 4.

Table 4: Smallholder Farmer' Ranking of Introduced Adaptation Strategies

\begin{tabular}{|c|c|c|c|c|}
\hline \multirow[t]{2}{*}{ Strategy } & \multicolumn{4}{|c|}{ Mean Rank } \\
\hline & Overall & $\begin{array}{l}\text { Region } \\
\text { Northern }\end{array}$ & Upper West & Upper East \\
\hline Soil and plant health strategies & 1.77 & 1.58 & 1.96 & 1.96 \\
\hline $\begin{array}{llll}\text { Improved varieties } & \text { and } & \text { breeds } \\
\text { strategies } & & & \end{array}$ & 2.67 & 2.68 & 2.73 & 2.58 \\
\hline Recommended agricultural strategies & 2.89 & 2.98 & 2.51 & 3.10 \\
\hline Other introduced strategies & 3.25 & 3.34 & 3.19 & 3.10 \\
\hline No introduced strategy & 4.42 & 4.42 & 4.60 & 4.26 \\
\hline \multicolumn{5}{|l|}{ Friedman Test Statistics } \\
\hline $\mathrm{N}$ & 320 & 159 & 80 & 81 \\
\hline Chi-Square & 514.422 & 292.087 & 134.635 & 102.721 \\
\hline $\mathrm{df}$ & 4 & 4 & 4 & 4 \\
\hline Asymp. Sig. & 0.000 & 0.000 & 0.000 & 0.000 \\
\hline
\end{tabular}

Source: Computations from field survey, 2011

Further, the results of the analysis reveal that the combined dataset and that by region/location are the same (i.e., the most ranked adaptation strategy introduced by research as well as the least ranked strategy). Soil and plant health strategies are ranked as the most effective introduced strategy in adapting to the effects of climate change and variability. Declining soil fertility resulting from climate change and other factors (e.g., soil erosion) are major problems facing smallholder farmers hence the adoption of soil and plant health related strategies helps to secure yield. Non-adoption of any of the introduced strategy is also unanimously ranked as being the least effective way of adapting to the effects of climate change and variability.

\section{Conclusion and Recommendations}

Technologies introduced by research are being used by smallholder farmers in northern Ghana to complement indigenous strategies to mitigate the effects of climate change and variability. The most important indigenous and introduced climate related adaptation strategies are: predicting the timing of the onset of the rainy season; and soil and plant health related strategies. This suggests that the availability of water during the growing period in the absence of irrigation, and the care of the crop are paramount for smallholders. Access to practical and reliable information on the onset of the rainy season and the likely pattern of rainfall throughout the season will help smallholders plan their cropping. This information will help complement smallholder farmers' indigenous knowledge. Soil and plant health technologies that are specific to the savanna agroecological zone should be generated and disseminated to farmers in northern Ghana. Farmers should be sensitized on the importance of cultivating certified seeds and their access to good quality seed assured through effective regulation and enforcement.

Acknowledgement: The study acknowledges the financial contribution of the global change SysTem for Analysis, Research and Training (START).

\section{References}

Altieri, M. A. \& Koohafkan, P. (2008). Enduring Farms: Climate Change, Smallholders and Traditional Farming Communities. Environment and Development Series 6. Third World Network. Penang, Malaysia. 
Below, T., Artner, A., Siebert, R. \& Sieber, S. (2010). Micro-level Practices to Adapt to Climate Change for African Small-scale Farmers. IFPRI Discussion Paper 00953. Washington, D.C.: International Food Policy Research Institute.

Boko, M., Niang, I., Nyong, A., Vogel, C., Githeko, A., Medany, M., Osman-Elasha, B., Tabo, R. \& Yanda, P. (2007). Africa. Climate Change 2007: Impacts, Adaptation and Vulnerability. Contribution of Working Group II to the Fourth Assessment Report of the Intergovernmental Panel on Climate Change, M.L. Parry, O.F. Canziani, J.P. Palutikof, P.J. van der Linden and C.E. Hanson, Eds., Cambridge University Press, Cambridge UK, 433-467.

Clements, R., Haggar, J., Quezada, A. \& Torres, J. (2011). Technologies for Climate Change AdaptationAgriculture Sector. X. Zhu (Ed.). UNEP Risø Centre, Roskilde, 2011.

Deressa T. T., Ringler C. \& Hassan, R. M. (2010). Factors Affecting the Choices of Coping Strategies for Climate Extremes: The Case of Farmers in the Nile Basin of Ethiopia. IFPRI Discussion Paper No. 01032. International Food Policy Research Institute, Washington, D.C, 25pp.

Easterling, W. E., Aggarwal, P. K., Batima, P., Brander, K. M., Erda, L., Howden, S. M. A., Kirilenko, A., Morton, J., Soussana, J. F., Schmidhuber, J. \& Tubiello, F. N. (2007). Food, fibre and forest products. Climate Change 2007: Impacts, Adaptation and Vulnerability. Contribution of Working Group II to the Fourth Assessment Report of the Intergovernmental Panel on Climate Change, Parry, M. L., Canziani, O. F., Palutikof, J. P., van der Linden, P. J., \& Hanson, C. E., Eds., Cambridge University Press, Cambridge, UK, 273-313.

Etwire, P. M., Al-hassan, R. M., Kuwornu, J. K. M. \& Osei-Owusu, Y. (2013). Application of Livelihood Vulnerability Index in Assessing Vulnerability and Climate Change in Northern Ghana. Journal of Environment and Earth Science, 3(2), 157-170.

Food and Agriculture Organisation FAO (2006). Livelihood Adaptation to Climate Variability and Change in Drought-Prone Areas of Bangladesh, Rome, Italy, 97.

Food and Agriculture Organisation FAO (2009a). Profile for Climate Change, Rome, Italy, 28pp.

Food and Agriculture Organisation FAO (2009b). Climate Change and Agriculture Policies; How to mainstream climate change adaptation and mitigation into agriculture policies? Rome, Italy, 76pp.

Food and Agriculture Organisation FAO (2010). Collaborative Change; A Communication Framework for Climate Change Adaptation and Food Security, Rome, Italy, 47pp.

Gbetibouo A. G. (2009). Understanding Farmers' Perceptions and Adaptations to Climate Change and Variability: The Case of the Limpopo Basin, South Africa. IFPRI Discussion Paper No. 00849. International Food Policy Research Institute, Washington, D.C, 36pp.

Government of Ghana (2011). Retrieved September 20, 2011 from http://www.ghana.gov.gh/index.php?option=com_content\&view=category\&layout=blog\&id=39\&Itemi $\mathrm{d}=194$

Hassan R. \& Nhemachena, C. (2008). Determinants of African farmers' Strategies for Adapting to Climate Change: Multinomial Choice Analysis. African Journal of Agricultural and Resource Economics, 2(1), 83104.

Legendre P. (2005). Species Associations: The Kendall Coefficient of Concordance Revisited. Journal of Agricultural, Biological, and Environmental Statistics, 10 (2), 226-245.

Loganathan R., Balasubramanian, R., Mani, K. \& Gurunathan, S. S. (2009). Productivity and Profitability Impact of Genetically Modified Crops - An Economic Analysis of Bt Cotton Cultivation in Tamil Nadu. Agricultural Economics Research Review, 22, 331-340.

Ministry of Food and Agriculture MoFA (2010). Agriculture in Ghana: FACTS AND FIGURES (2009), Accra, Ghana, 53pp.

Molua L. E. \& Lambi, C. M. (2006). The Economic Impact of Climate Change on Agriculture in Cameroon, Centre for Environmental Economics and Policy in Africa (CEEPA), University of Pretoria, South Africa, 33pp.

Morton, F. J. (2004). The Impact of Climate Change on Smallholder and Subsistence Agriculture, Proceedings of the National Academy of Sciences (PNAS), 104 (50), 19680-19685.

Nhemachena, C. \& Hassan, R. (2007). Micro-Level Analysis of Farmers' Adaptation to Climate Change in Southern Africa. IFPRI Discussion Paper No. 00714. International Food Policy Research Institute, Washington, D.C, 30pp. 